\title{
El hacer saber de los motivos de los estudiantes que han tomado las armas en la escuela. Elementos para pensar la violencia escolar extrema
}

\author{
The making known of the motives of students who have used \\ weapons in school. Elements to reflect on extreme school \\ violence
}

DOI: $\underline{10.32870 / \text { dse.v0i19.545 }}$

\section{María Gutiérrez Zúñiga*}

\begin{abstract}
Resumen
Este trabajo parte de la elaboración de un recuento histórico de los ataques escolares realizados por estudiantes armados, los cuales constituyen una de las formas del fenómeno internacional contemporáneo de la violencia escolar extrema. Dicho recuento, basado en información aportada por textos académicos, artículos periodísticos y bases de datos electrónicas, dio lugar a la localización y construcción de 65 casos ocurridos entre agosto de 1966 y marzo de 2018.

El presente artículo da cuenta de una estadística significativa del fenómeno, derivada de los datos del conjunto casuístico. Después se aboca a tomar nota y analizar lo que estos casos han hecho saber sobre los motivos, propósitos y sentidos de los atentados, una vez que, conjuntándolos, es posible encontrar ciertas coordenadas comunes entre ellos. Finalmente, a partir de este análisis acerca del saber de un acto $^{1}$ - acto cuya violencia y radicalidad interpelan la misión por antonomasia de la escuela en cuanto que creadora y posibilitadora de civilización y, al mismo tiempo, a la sociedad y a la cultura en los que se produjo- se establecen algunas articulaciones con propuestas teóricas de Gilles Deleuze, Félix Guattari y Michel Foucault, las cuales abren cierta vía para pensar la problemática en cuestión.
\end{abstract}

Palabras clave: violencia - escuela - estudiantes - saber - modernidad.

\section{Abstract}

This paper starts with a historical account of school attacks by armed students, which are one form of the current international phenomenon of extreme school violence. Based on information from academic texts, news articles and electronic data bases, this account led to the location and construction of 65 cases that took place between August 1966 and March 2018. The paper then presents a significant statistic of

\footnotetext{
* Analista y académica del Departamento de Estudios en Educación del Centro Universitario de Ciencias Sociales y Humanidades de la Universidad de Guadalajara. Su trabajo como docente e investigadora se inscribe en la línea denominada "Subjetividad y Educación". México. mariaguzu@gmail.com

1 Saber que puede producirse solo a posteriori de la comisión del acto, dados los órdenes heterogéneos —aunque relacionados—a los que saber $y$ acto pertenecen.
} 
the phenomenon based on data from the whole set of cases and analyzes what these cases have revealed about the motives, purposes and meanings of the attacks in order to find common features among them. Finally, based on this analysis about the knowledge of an act - an act whose violence and radical nature challenge the essential mission of the school as a creator and enabler of civilization and, at the same time, pose a threat to the society and the culture in which it took place - some links are established with the theoretical approaches of Gilles Deleuze, Félix Guattari and Michel Foucault, which open a path to reflect on the issue at hand.

Key words: violence - school - students - knowledge - modernity.

All I want is killing, hurting and scaring as much people as possible! Sometimes I write shit in English because I want everybody to understand what the hell I'm talking about! ${ }^{2}$

Bastian Bosse, atacante escolar. Emsdetten, Alemania, 2006.

Desde el punto de vista del Estado, la originalidad del hombre de guerra, su excentricidad, aparece necesariamente bajo una forma negativa: estupidez, deformidad, locura, ilegitimidad, usurpación, pecado...

Guilles Deleuze y Felix Guattari Mil mesetas. Capitalismo y esquizofrenia.

La política es la posibilidad de un ámbito plural, en el que quienes participan se revelan como alguien y le otorgan durabilidad al mundo.

Hannah Arendt ¿Qué es política?

\section{Introducción}

El presente artículo se desprende del trabajo de investigación en curso, el cual se realiza desde el proyecto general denominado "Infancias, adolescencias y experiencias escolares contemporáneas. Nuevas tendencias en la educación y biopolítica", a cargo de la autora. El interés por formular y abordar ciertas interrogantes acerca de las experiencias de "los nuevos"3 en su pasaje por la escuela, en el contexto de la época presente, responde al valor generador que tienen dichas experiencias en la producción de formas de subjetivación, las cuales idealmente establecen condiciones para que los estudiantes se sitúen y

2 Anónimo (22 de noviembre, 2016).

3 Término que utilizaban los antiguos griegos y que Arendt retoma en su obra para nombrar a los niños y jóvenes en su estatuto de potencia de la historia.

Diólo \os 
contribuyan a la construcción de un mundo que sea habitable para todos los seres humanos. ${ }^{4}$ Hannah Arendt (2016) parte del supuesto de que estas experiencias tienen dicho valor para considerar que la educación escolar tenía un carácter prepolítico.

A partir de la guía marcada por el interés descrito, ciertos acontecimientos nacionales e internacionales de la actualidad condujeron a una pregunta acerca de un fenómeno sociocultural propio de la modernidad: ${ }^{5}$ la ocurrencia - hoy día no poco frecuente- de actos de violencia extrema en instituciones escolares, llevados a cabo particularmente por estudiantes. ${ }^{6}$ Tales ataques, tiroteos e incluso masacres, podrían conformar — cada uno y en su conjunto- manifestaciones o testimonios extremos en acto, de cierta gama de experiencias del paso de los alumnos por la institución educativa, los cuales es importante estudiar dado el objeto de estudio del proyecto general de investigación, a saber: las experiencias escolares contemporáneas de infancia y adolescencia. ¿Qué es lo que estos atentados hacen saber acerca de las experiencias escolares de sus perpetradores y, más específicamente, acerca de los motivos y el sentido de planearlos y llevarlos a cabo? Esta es la pregunta central que el presente texto se plantea abordar.

\section{Trayectoria metodológica general}

Intentar responder a esta pregunta requirió, en primera instancia, trazar una ruta de exploración a través de la historia y el estatus del fenómeno en el nivel internacional. ${ }^{7}$ Para hacerlo, se consultó el internet en busca de textos académicos, artículos periodísticos y bases de datos fiables. Recurrir a estas fuentes de información permitió conocer las maneras en que los hechos de violencia escolar extrema se registran y se estudian, y las maneras en que se informa a la sociedad acerca de ellos. También hizo posible ver que la información acerca de estos hechos, gracias al internet y a las redes sociales, se difunde de manera tal que queda al alcance de una muy extensa población de estudiantes en todas partes del mundo.

En el proyecto de investigación de base antes mencionado se establece un recorte etario en la población escolar a estudiar, el cual incluye solo niños, niñas y adolescentes. Pero los resultados de la in-

4 Frente al progreso y el desarrollo de la tecnología, desplegados a partir del capitalismo y de las grandes guerras del siglo XX, la categoría de "humano" ha quedado ampliamente problematizada, particularmente por diversos filósofos y críticos de la modernidad: Heidegger, Arendt y Foucault, por ejemplo. Pero la sostengo en este texto como un punto de referencia muy importante para poder pensar lo que está en juego en el problema de violencia que me he planteado abordar.

5 Se entiende aquí a la modernidad como el periodo, aún en curso, posterior a la Segunda Guerra Mundial.

6 Fue posible ver la importancia del estudio de este fenómeno internacional cuando México fue también tocado por él, particularmente a partir de que tuviera lugar el tiroteo llevado a cabo por un alumno de secundaria en el Colegio Americano del Noroeste, en la ciudad de Monterrey, Nuevo León, el 18 de enero de 2017. La ensambladura y el potencial destructivo de este hecho habían sido hasta entonces inéditos en el país; y esto lo asociaba precisamente con el fenómeno recién descrito: la serie de ataques escolares armados, efectuados por estudiantes, que se han producido en muchos países del mundo — particularmente en Estados Unidos_ desde hace varias décadas.

7 Agradezco a la Dra. Ana Luisa González por haberme sugerido esto durante nuestra mesa de trabajo acerca de la educación básica, en el Coloquio de Investigación del DEEDUC en agosto de 2017.

Diólopos 
vestigación acerca de las características de la extensa serie de ataques escolares a manos de estudiantes condujeron a considerar necesario incluir también a jóvenes de entre 18 y 29 años.

La enciclopedia digital Wikipedia contiene un artículo titulado "Anexo: Ataques perpetrados en centros educativos" 8 en el que se hace el registro más extenso del internet sobre ataques escolares, e incluye desde los casos más antiguos hasta los más recientes pues el artículo se actualiza periódicamente. Se utilizó este artículo únicamente para conocer los nombres de atacantes e instituciones educativas donde han ocurrido ataques escolares, para después buscar información acerca de ellos en fuentes fiables tales como los antes mencionados artículos periodísticos, textos académicos y entradas en bases de datos con estándares científicos. Se realizó así un registro de todos los casos que en principio parecían relevantes para esta investigación: se reunieron las fichas o datos más sobresalientes de un total de 116 ataques a escuelas ocurridos en varias partes del mundo entre julio de 1764 y el 31 de marzo de 2018, fecha en la que se cerró la muestra.

Una labor requerida a continuación fue determinar cuáles de esos 116 ataques constituyen efectivamente hechos del tipo que concierne a la presente investigación. Con base en un criterio que se explicará más adelante, quedaron seleccionados solo $65 .{ }^{9} \mathrm{~A}$ partir del esqueleto de datos que las fichas elaboradas presentan, se construyeron los casos, cada uno correspondiente a un ataque, ${ }^{10}$ enriqueciéndolo con la información consultada y pareada en múltiples fuentes fiables de información. ${ }^{11}$

Tras dar cuenta de lo anterior, se volverá sobre los pasos del inicio del proceso metodológico de la investigación.

\section{Los primeros elementos de diferenciación y elaboración de definiciones en la conformación del grupo de casos}

El examen de las 116 fichas elaboradas permitió encontrar ciertas diferencias entre los múltiples casos, de las cuales se dará cuenta mediante una tipología de los ataques elaborada para esta investigación:

Tipo 1: rebeliones sociopolíticas en instituciones educativas. Aquí se agrupan hechos que generalmente se piensan vinculados a insurrecciones y luchas de carácter sociopolítico, independientemente de la valoración sobre su legitimidad. Estos hechos implican a grupos en conflicto que son identificables por la

$8 \mathrm{Cf}$. https://es.wikipedia.org/wiki/Anexo:Ataques_perpetrados_en_centros_educativos

9 Ciertos indicios apuntan hacia la vigencia de una posible política internacional de filtrar o seleccionar a cuáles se les da cobertura informativa, con base en su gravedad e implicaciones políticas. Y es que, de acuerdo con lo que será planteado en este trabajo, cada acto perpetrado de violencia escolar opera como precursor y modelo para ataques posteriores. Esta es una cuestión delicada, sobre todo en un contexto en el que el fenómeno de la violencia escolar extrema a manos de estudiantes se incrementa de forma preocupante.

10 Escribo el término con itálicas para que el empleo que hago de él no corresponde al de su acepción médico-jurídica, sino a la acepción de entidad de conocimiento que no preexiste a la investigación, sino que se sostiene a partir de su reconstrucción histórica.

11 Hay que precisar que, dadas las diferencias en cuanto a la gravedad y la importancia de cada uno de los ataques registrados en internet, los tipos de información presentada de cada uno de ellos no son homogéneos. En consecuencia, el formato y el contenido de cada uno de los 65 casos elaborados es singular.

Diáloqos 
sociedad con cierta antelación a sus ataques. Por ejemplo, ataques declaradamente terroristas o rebeliones estudiantiles reprimidas por el Estado o la policía.

Tipo 2: hechos azarosos de violencia escolar extrema. Casos de este tipo son ataques violentos que por casualidad alcanzan a la institución escolar, pero que son producto de pugnas o conflictos en principio ajenos a ella, por lo que los perpetradores no son agentes de la educación (directivos, profesores, estudiantes o padres de familia), aunque sus víctimas sí lo son. Por ejemplo, el caso Bay Ningyang, de 18 años (Henan, China, 2006), quien respondió al rechazo de la chica que amaba, maestra en una escuela primaria, incendiando el salón de clases en que habría encerrado tanto a la joven como a sus alumnos.

Tipo 3: hechos de violencia escolar propiamente dicha. Aquí se conjuntan ataques efectuados de manera inesperada en instituciones escolares, generalmente por parte de un agente de la educación, raramente dos. Las fuerzas en pugna en ataques de este tipo no habían sido instituidas antes del ataque, ni reconocidas colectivamente como tales; por el contrario, todo indica que es a partir de la realización del atentado mismo que se ponen de manifiesto y fuerzan su reconocimiento público mediante el carácter subversivo y la potencia destructiva del atentado. De acuerdo con una de las tesis principales que sostengo en este trabajo, la dimensión política ${ }^{12}$ no es ajena a la producción de este tipo de hechos violentos. Más adelante se abordará esta cuestión con mayor detenimiento.

\section{Desde hace 60 años los estudiantes toman las armas}

De acuerdo con esta tipología, los 116 ataques mencionados en el artículo se organizaron de esta manera:

Ataques del tipo 1:13

Ataques del tipo 2: 28

Ataques del tipo 3:75

Dado que el proyecto de investigación se propone seguir y abordar experiencias contemporáneas de infancia y adolescencia en la escuela, el tipo de eventos que resultaron particularmente interesantes para esta investigación fueron los del tipo 3 y, más específicamente, aquellos en los que son los estudiantes quienes perpetran los ataques. El conjunto de estos últimos ataques constituye el grupo de los 65 casos antes mencionado. Así, del grupo tipo 3 se filtró $13.33 \%$ de los ataques: dos cometidos por dos directivos varones, seis cometidos por seis profesores varones, uno cometido por una profesora, y un ataque cometido por un padre de familia, los cuales suman diez ataques filtrados en total.

Hay dos indicios muy importantes que notar en la lista cronológica de ataques escolares. Los seis primeros ataques del tipo 3 que aparecen registrados —ocurridos entre 1764 y 1959 o sea, en un pe-

12 En el sentido que Guattari y Rolnik (2006) le dan al término, relacionado con las posibilidades de acción y agencia de los menores de edad frente a sus circunstancias de vida.

Diólo@os sobre Educación

año 10 | número 19 | julio-diciembre 2019 | ISSN 2007-2171 
riodo de casi 200 años - fueron llevados a cabo por tres maestros, dos directivos y un padre de familia; ninguno por estudiantes. Pero a partir de 1966 ocurre un cambio radical en dos direcciones. En adelante, por una parte, la frecuencia de eventos registrados se incrementa aceleradamente, y por la otra, los actores educativos perpetradores predominantes dejaron de ser los adultos y comenzaron a ser los estudiantes, quienes avasalladoramente tomaron el liderazgo en este conteo.

El hallazgo de estos indicios alentó la búsqueda, sobre todo ante la evidencia del surgimiento localizable de cierto fenómeno en la historia. Dado que los ataques de violencia escolar extrema conforman una cuestión problemática particular para toda civilización, es interesante pensar en lo que implica este giro operado mundialmente tan solo en las últimas seis décadas.

\section{Primer nivel de abordaje: travesía y otros hallazgos en el total de ataques escolares}

A continuación, se hará la presentación gráfica de un primer abordaje y análisis cuantitativo de la información encontrada relativa al tema del presente texto.

El cuadro inicial compendia los 65 ataques escolares llevados a cabo por estudiantes, y muestra sus datos más relevantes: año y país en que ocurrió cada uno, edad y apellido de el/los perpetrador/es, número de víctimas mortales y de heridos, y si el atentado finalizó o no con el suicidio del perpetrador.

Cuadro 1. Ataques estudiantiles. Compendio de los 65 casos registrados ${ }^{13}$

\begin{tabular}{|c|c|c|c|c|c|c|c|}
\hline No. & Año & País & Edad & Apellido & Muertos & Heridos & Suicidio \\
\hline 1 & 1966 & EEUU & 25 & Whitman & 16 & 32 & No \\
\hline 2 & 1974 & EEUU & 17 & Barbaro ${ }^{14}$ & 3 & 9 & No \\
\hline 3 & 1975 & Canadá & 16 & Slobodian & 2 & 13 & Sí \\
\hline 4 & 1975 & Canadá & 18 & Poulin & 2 & 6 & Sí \\
\hline 5 & 1979 & EEUU & 16 & Spencer & 2 & 9 & No \\
\hline 6 & 1989 & EEUU & 24 & Purdy & 5 & 31 & Sí \\
\hline 7 & 1989 & Canadá & 25 & Lépine & 14 & 14 & Sí \\
\hline 8 & 1991 & EEUU & 28 & Lu & 5 & 1 & Sí \\
\hline 9 & 1992 & EEUU & 20 & Houston & 4 & 10 & No \\
\hline 10 & 1996 & EEUU & 14 & Loukaitis & 3 & 1 & No \\
\hline 11 & 1997 & EEUU & 16 & Ramsey & 2 & 2 & No \\
\hline
\end{tabular}

13 La información de los casos 1, 4-16, 20, 25-27, 29, 30, 33, 35, 36, 42 y 44 fue tomada de Langman (2015). La de los casos 3, 19, 28, 31, 38, 39, $45,51,55,58$ y 64 fue tomada de la base de datos electrónica School Shooters.info, la cual se alimenta de múltiples artículos académicos y periodísticos. Las fuentes de información de todos los demás casos están indicadas en notas al pie ligadas a cada una de las entradas correspondientes en este cuadro.

14 McFadden (31 de diciembre, 1974).

Diálo pos 


\begin{tabular}{|c|c|c|c|c|c|c|c|}
\hline 12 & 1997 & EEUU & 16 & Woodham & 3 & 7 & No \\
\hline 13 & 1997 & EEUU & 17 & Carneal & 3 & 5 & No \\
\hline 14 & 1998 & EEUU & 11 y 13 & Golden y Johnson & 5 & 10 & No \\
\hline 15 & 1998 & EEUU & 15 & Kinkel & 4 & 25 & No \\
\hline 16 & 1999 & EEUU & 18 y 17 & Harris y Klebold & 15 & 24 & Sí, ambos \\
\hline 17 & 2000 & EEUU & 6 & Owens $^{15}$ & 1 & 0 & No \\
\hline 18 & 2000 & Argentina & 19 & Romero ${ }^{16}$ & 1 & 1 & No \\
\hline 19 & 2001 & EEUU & 15 & Williams & 2 & 13 & No \\
\hline 20 & 2002 & Alemania & 19 & Steinhäuser & 16 & 7 & Sí \\
\hline 21 & 2003 & EEUU & 17 & McLaughling $^{17}$ & 1 & 1 & No \\
\hline 22 & 2004 & China & 24 & Jiajue $^{18}$ & 4 & 0 & No \\
\hline 23 & 2004 & Japón & 11 & Tsuji19 & 1 & 0 & No \\
\hline 24 & 2004 & Argentina & 15 & Solich $^{20}$ & 3 & 5 & No \\
\hline 25 & 2005 & EEUU & 16 & Weise & 9 & 7 & Sí \\
\hline 26 & 2006 & Canadá & 25 & Gill & 1 & 19 & Sí \\
\hline 27 & 2006 & EEUU & 15 & Hainstock & 1 & 0 & No \\
\hline 28 & 2006 & Alemania & 18 & Bosse & 0 & 37 & Sí \\
\hline 29 & 2007 & EEUU & 23 & Cho & 32 & 17 & Sí \\
\hline 30 & 2007 & Finlandia & 18 & Auvinen & 8 & 12 & Sí \\
\hline 31 & 2008 & EEUU & 23 & Williams & 2 & 0 & Sí \\
\hline 32 & 2008 & EEUU & 14 & Mclnerney ${ }^{21}$ & 1 & 0 & No \\
\hline 33 & 2008 & EEUU & 27 & Kazmierczac & 5 & 17 & Sí \\
\hline 34 & 2008 & Sudáfrica & 18 & Harmse $^{22}$ & 1 & 3 & No \\
\hline 35 & 2008 & Finlandia & 22 & Saari & 10 & 1 & Sí \\
\hline 36 & 2009 & Alemania & 17 & Kretchmer & 15 & 9 & Sí \\
\hline 37 & 2009 & Grecia & 19 & Patmanidis $^{23}$ & 1 & 3 & Sí \\
\hline 38 & 2011 & EEUU & 17 & Butler & 1 & 2 & Sí \\
\hline 39 & 2011 & Brasil & 23 & Menezes de Oliveira & 12 & 12 & Sí \\
\hline 40 & 2011 & Brasil & 10 & Mota $^{24}$ & 1 & 1 & Sí \\
\hline
\end{tabular}

15 Finley (2014).

16 Dos Santos Coelho (4 de agosto, 2015).

17 Anónimo (25 de septeimbre, 2015).

18 Zhi y Yiming (17 de marzo, 2004).

19 Anónimo (2 de junio, 2004).

20 Anónimo (15 de febrero, 2018).

21 Corbett (6 de diciembre, 2017).

22 Ajam (23 de agosto, 2008). 


\begin{tabular}{|c|c|c|c|c|c|c|c|}
\hline 41 & 2011 & EEUU & 22 & Ashley ${ }^{25}$ & 2 & 0 & Sí \\
\hline 42 & 2012 & EEUU & 17 & Lane & 3 & 3 & No \\
\hline 43 & 2012 & EEUU & 25 & Krumm $^{26}$ & 3 & 0 & Sí \\
\hline 44 & 2012 & EEUU & 20 & Lanza $^{27}$ & 27 & 2 & Sí \\
\hline 45 & 2013 & EEUU & 23 & Zawahri & 9 & 4 & No \\
\hline 46 & 2013 & EEUU & 17 & Alfaro ${ }^{28}$ & 1 & 3 & No \\
\hline 47 & 2014 & EEUU & 23 & Cousins ${ }^{29}$ & 1 & 0 & No \\
\hline 48 & 2014 & Rusia & 15 & Gordeyev 30 & 2 & 1 & No \\
\hline 49 & 2014 & Reino Unido & 15 & Cornick $^{31}$ & 1 & 0 & No \\
\hline 50 & 2014 & México & 15 & Yoevani32 & 1 & 0 & No \\
\hline 51 & 2014 & EEUU & 15 & Fryberg & 4 & 1 & Sí \\
\hline 52 & 2014 & Rusia & Varios & Grupo de estudiantes 33 & 1 & 0 & No \\
\hline 53 & 2015 & España & 13 & Anónimo 34 & 1 & 4 & No \\
\hline 54 & 2015 & Guatemala & 19 & Lemus 35 & 0 & 3 & No \\
\hline 55 & 2015 & EEUU & 26 & Harper-Mercer & 9 & 7 & No \\
\hline 56 & 2015 & Suecia & 21 & Pettersson ${ }^{36}$ & 3 & 2 & No \\
\hline 57 & 2017 & México & 15 & Guevara37 & 2 & 3 & Sí \\
\hline 58 & 2017 & Francia & 16 & Barbey & 0 & 4 & No \\
\hline 59 & 2017 & EEUU & $?$ & Anónimo $3^{8}$ & 2 & 4 & Sí \\
\hline 60 & 2017 & México & 17 & Piña & 2 & 4 & Sí \\
\hline
\end{tabular}

23 Anónimo (11 de abril, 2009).

24 Anónimo (23 de septiembre, 2011).

25 Anónimo (10 de diciembre, 2011).

26 Hughes (2 de diciembre, 2013).

27 El caso de Adam Lanza podría parecer similar al caso antes mencionado de Bay Ningyang, pues atacó con un arma de fuego a los alumnos de primaria de su madre, y a varios directivos de su escuela (Sandy Hook Elementary School) después de asesinarla a ella. Sin embargo, el caso de Lanza sí fue contabilizado dentro del conjunto de casos relevantes para esta investigación por dos motivos: el primero, el hecho de que Lanza había estudiado en esa escuela y, el segundo, el hecho de que había tenido el día anterior al ataque una fuerte discusión con algunos directivos de la escuela, dos de los cuales fueron asesinados durante el ataque; se ha considerado que esta discusión constituyó uno de los precipitantes del ataque de Lanza. Ambos hechos sugieren que, a diferencia del ataque de Ningyang, el ataque de Lanza sí estaba relacionado con problemáticas escolares.

28 Donaghue (5 de septiembre, 2015).

29 Dodge (29 de octubre, 2014).

30 Stewart (3 de febrero, 2014).

31 Pidd (3 de noviembre, 2014).

32 Anónimo (20 de junio, 2014).

33 Anónimo (30 de diciembre, 2014).

34 Blanchar y Congostrina (20 de abril, 2015).

35 Paxtor (21 de abril, 2015). 


\begin{tabular}{|c|c|c|c|c|c|c|c|}
\hline 61 & 2017 & Argentina & 15 & Tolosa39 & 1 & 0 & Sí \\
\hline 62 & 2018 & Rusia & 15 & Anónimo40 & 0 & 6 & No \\
\hline 63 & 2018 & EE.UU & 15 & Anónimo41 & 2 & 19 & No \\
\hline 64 & 2018 & EE.UU & 19 & Cruz & 17 & 17 & No \\
\hline 65 & 2018 & EE.UU & 17 & Rollins $^{42}$ & 1 & 2 & Sí ¿? \\
\hline
\end{tabular}

Cuadro 2. Frecuencia de los ataques

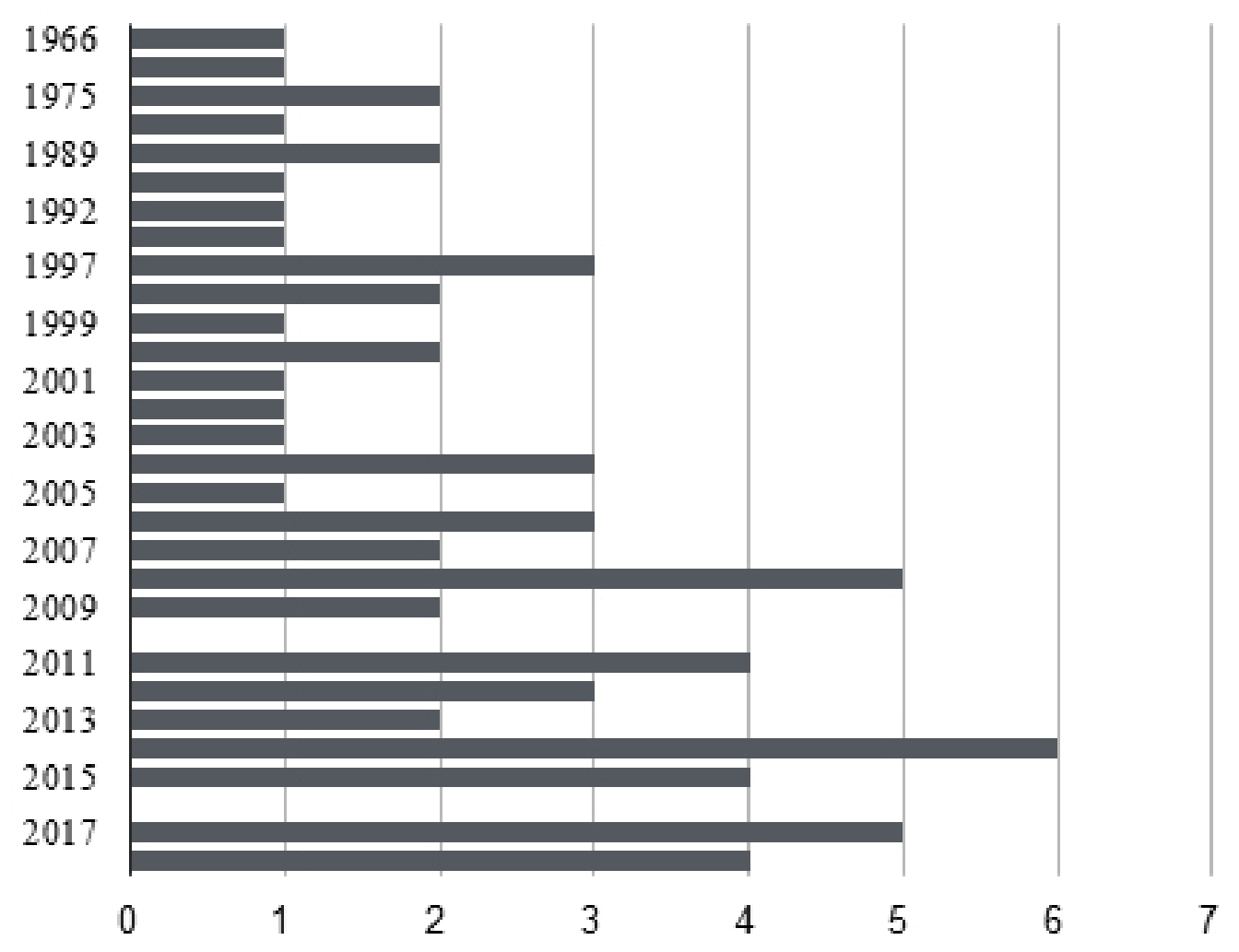

36 Bryant (23 de octubre, 2015).

37 Campos Garza (18 de enero, 2017).

38 Solomon (3 de mayo, 2017).

39 Anónimo, (8 de agosto, 2017).

40 Anónimo (19 de enero, 2018).

41 Gostaninan (Johnson y Siemaszko, 23 de enero de 2018).

42 Anónimo (20 de marzo, 2018).

Diólo gos 
Es importante hacer una serie de observaciones en relación con este cuadro y el que le antecede. El primer ataque escolar a manos de un estudiante del que se tiene registro ocurrió en 1966, y hasta la fecha, se ha acelerado el ritmo con el que se incrementan los casos cada año. En efecto, como podrá advertirse, al inicio de este periodo había intervalos de hasta 8 años entre un evento y otro; pero a partir de 1996, estos sucesos tienen lugar cada año — con excepción de 2010 y 2016—, ${ }^{43}$ e incluso varias veces por año: solo en 2014 hubo seis casos, cinco en 2017, y cuatro casos tan solo en los primeros tres meses de 2018. ${ }^{44}$ Estos tres son los años que se plantean con mayor incidencia. Además, de hecho, el promedio de ataques anuales parece ir en aumento. El siguiente cuadro muestra el número de casos en cada país, y el porcentaje correspondiente del total de casos registrados hasta la fecha.

Cuadro 3. Cantidad y porcentaje de ataques registrados por país

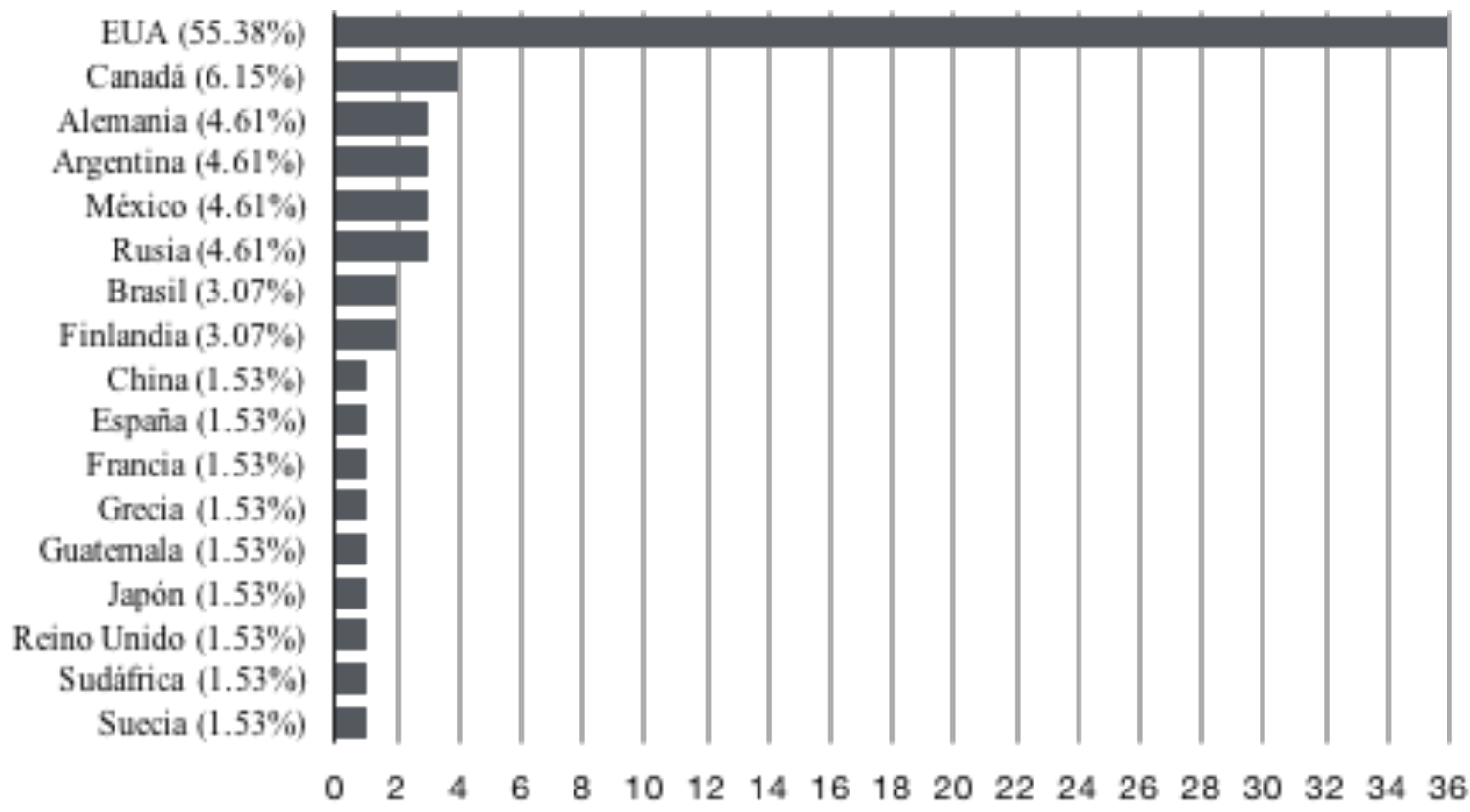

Cuadro 4. Total de ataques y porcentaje por continente

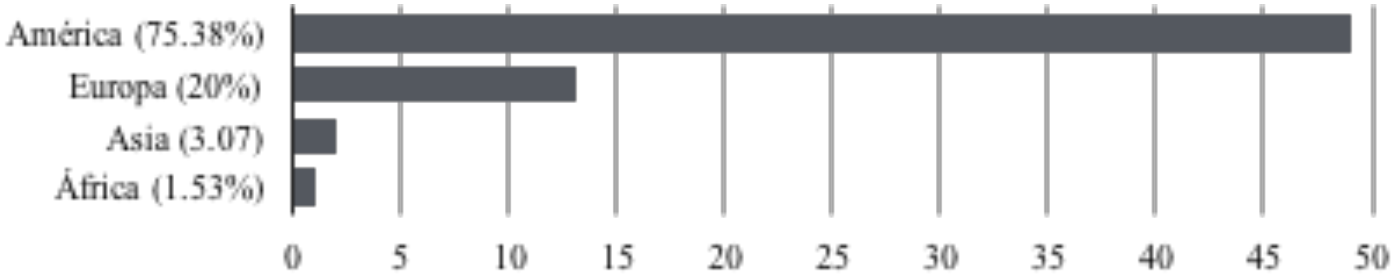

43 Hay dos casos registrados en 2016, pero ninguno de ellos aporta los datos necesarios para considerarlos con certeza dentro del grupo de los ataques escolares perpetrados por estudiantes.

44 De acuerdo con ciertos noticieros, tan solo en EEUU, en 2018 han ocurrido 18 ataques armados, aunque no todos han reportado víctimas mortales. C.f. https://www.univision.com/noticias/tiroteos/

Diólo gos 
En relación con lo que se ha mostrado en los cuadros anteriores, quedan puestos claramente en relieve tres hechos: 1) que los ataques en Estados Unidos han ocurrido constantemente desde el momento en que se hizo el primer registro de un ataque de este tipo, 2) son mundialmente los más numerosos, y 3) ocurren cada vez con más frecuencia. Todo indica que esta tendencia estadística genera, precisamente, que América encabece este conteo, en relación con los otros continentes. El abordaje de esta cuestión podrá ser objeto de ulteriores estudios.

\section{Edad de los atacantes e incidencia de los ataques}

Otro dato observado que resulta significativo es el de la edad de los perpetradores. Al analizar esta información es necesario tomar en cuenta lo siguiente: los ataques 14 y 16 fueron realizados cada uno por dos jóvenes; el ataque 52 fue llevado a cabo por un número indeterminado de jóvenes preuniversitarios cuyas edades no fueron precisadas; $y$, por último, el ataque 63 fue cometido por un joven de edad desconocida. Dado esto, la cantidad de atacantes es mayor que la cantidad de ataques; pero en el cuadro siguiente se registran las edades de 65 atacantes puesto que los casos en los que participan dos compensan los casos en los que se desconoce la edad de los atacantes.

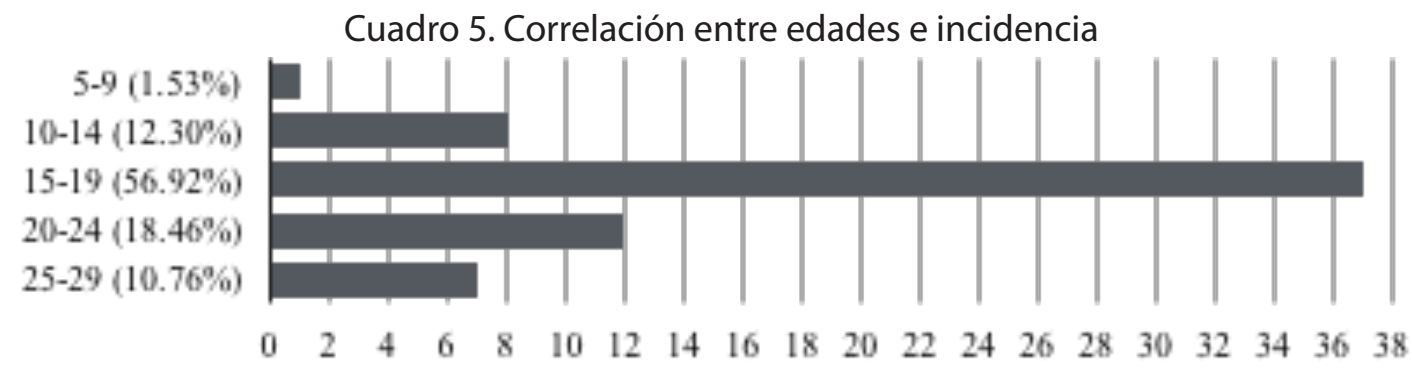

De los 37 sujetos del grupo de atacantes entre 15 y 19 años, 27 eran menores de edad ${ }^{45}$ al momento de llevar a cabo al ataque; los otros diez eran mayores de edad.

En esta contabilización puede observarse claramente que los atacantes menores de edad constituyen el grupo más grande, conformado por 36 adolescentes, niños y niñas, y equivalente a $55.38 \%$ del total de sujetos que formaron parte de esta muestra. Es importante notar que el atacante más joven tenía tan solo 6 años. Los jóvenes mayores de edad, por otro lado, conforman un grupo de 29 , y constituyen $44.61 \%$.

Las cifras anteriores revelan también que el grupo etario al que más sujetos pertenecían al momento de llevar a cabo el ataque es el que comprende edades entre 15 y 19 años, precisamente

45 Se considera aquí a los 18 años como el comienzo de la mayoría de edad. No en todos los países del mundo adoptan este parámetro, pero sí todos los países a los que los sujetos en cuestión pertenecen — salvo porque hay cuatro estados y territorios estadounidenses en los que la mayoría de edad se alcanza al cumplir los 21 años; pero este otro criterio no afecta el estatus de minoría de edad de los 27 sujetos contabilizados como menores de edad en el grupo de atacantes de entre 15 y 19 años, pues ninguno de ellos vivía en alguno de estos estados o territorios. 
aquellas que corresponden a la etapa de transición entre la adolescencia y juventud. En segundo lugar, se encuentra el grupo etario superior, el de jóvenes entre 20 y 24 años.

La explicación de la presencia predominante de jóvenes menores de edad en este conteo, así como del modo en que ellos accedieron a armas de fuego que la ley les prohíbe utilizar, son cuestiones para seguir estudiando, en cuanto que importa investigar qué es lo que estos hechos nos hacen saber y a qué apuntan en el futuro. Estas interrogantes, sin embargo, habrán de ser objeto de estudios posteriores.

\section{La dimensión diferencial de género entre los atacantes}

De los 65 casos de ataques registrados y estudiados, solo cuatro fueron perpetrados por estudiantes del sexo femenino, correspondientes a 6.15\%. Estas cuatro estudiantes tenían 16, 23, 11 y 15 años respectivamente, considerando el orden cronológico de sus ataques. Del total de los atacantes, 93.85\% era del sexo masculino.

En relación con los cuatro ataques realizados por chicas, en lo relativo a sus móviles y modus operandi llama la atención que solo una de ellas, Brenda Ann Spencer (1979, EEUU, caso 5), procedió de un modo similar al de algunos varones que habían llevado a cabo ataques masivos años atrás: actuó como francotiradora contra una escuela de niños. Los dos casos siguientes fueron perpetrados a manera de venganza directa contra amigas: Latina Williams (2001, EEUU, caso 19) utilizó un arma de fuego, y Natsumi Tsuji (2004, Japón, caso 23), un arma punzocortante —más precisamente, un cúter. El último caso que involucró a una joven fue el de Lara Tolosa (2017, Argentina, caso 61), quien, tras amenazar a varios estudiantes de su salón de clases que le imponían bullying, apuntándoles con un arma de fuego, finalmente disparó contra sí misma y murió.

Esta diferencia radical, atravesada por el género en las estadísticas de los ataques escolares, marca una nueva posibilidad de investigación.

Tipos de armas utilizados en los ataques

El siguiente cuadro muestra la contabilización del tipo de armas utilizadas por los estudiantes para llevar a cabo los ataques:

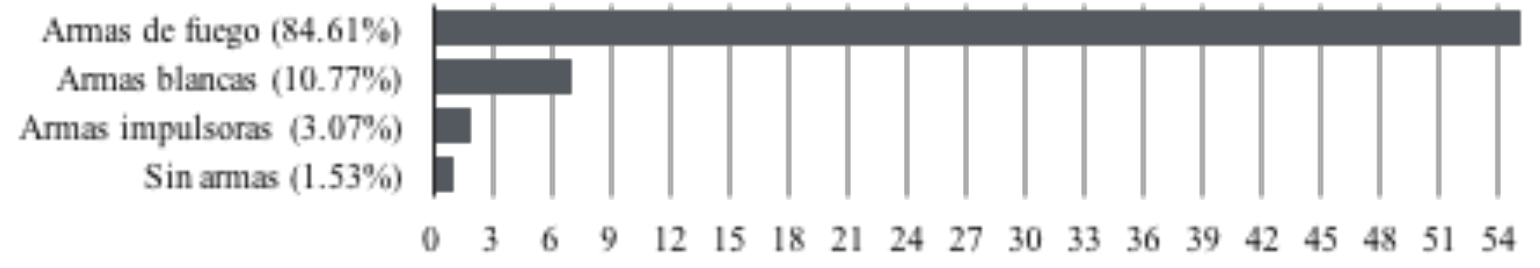

Entre las armas de fuego utilizadas se encontraban pistolas, rifles y metralletas de diferentes grados de poder y peligrosidad; entre las armas blancas había cuchillos, espada y hacha. Las dos armas impulsoras usadas fueron un arco y una ballesta. Dentro de la última categoría he incluido un caso en el que

Diálo os

sobre Educación

año 10 | número 19 | julio-diciembre 2019 | ISSN 2007-2171 
un estudiante murió tras un episodio de bullying en el que se lo torturó; eventualmente, la situación se salió de control y el estudiante falleció.

¿Qué es lo que estos jóvenes, adolescentes y niños lanzan mediante sus ataques y el uso de las armas en sus escuelas? Abordaremos esta pregunta a profundidad más adelante.

\section{Incidencia de suicidio}

El número de estudiantes que cometieron suicidio propiamente dicho al final de su ataque es considerable: oscila entre los 29 y los $30,{ }^{46}$ que es equivalente a $46.15 \%$ del total de los atacantes. ${ }^{47}$ No obstante, en el resto de los casos encontramos 15 en los que la relación entre suicidio y ataque estuvo vigente por al menos uno de los siguientes motivos:

a) El suicidio del atacante ocurrió ulteriormente en prisión.

b) El modo de operar del atacante hacía muy probable que llegara a ser abatido por la policía. Algunos jóvenes incluso dejaron previamente una nota de despedida, o subieron a la red escritos, videos o fotografías antes del ataque, en los que insinuaban, anunciaban o ensayaban la posibilidad del suicidio como su salida.

c) Tras su ataque pidieron a personas que estaban a su alrededor que les quitaran la vida.

Esta alta correlación entre ataque y suicidio hace ver una especie de mutua implicación en la lógica del acto mismo del atentado. Esta cuestión se abordará enseguida.

\section{Segundo nivel de abordaje: localizar el hacer saber de los casos en torno a sus motivos. Orígenes y filiaciones del trabajo de caso en esta investigación}

Para los fines de este texto, el término caso -empleado para referirnos a cada uno de los ataques escolares estudiados - no se usa en su acepción médico-jurídica sino en una acepción peculiar en la que un caso es una entidad de conocimiento — cara al psicoanálisis lacaniano- que no preexiste a su estudio sino que se sostiene a partir de su propia construcción/reconstrucción histórica. La elaboración de un caso así entendido implica una labor de búsqueda de datos por los medios al alcance, y de recopilación —lo más amplia, completa y documentada posible, pero sin pretenderse exhaustiva— de los elementos considerados constitutivos del caso.

46 Dicha oscilación se debe a que en el caso de Rollins (2018, EEUU, caso 65) existe incertidumbre acerca de si su muerte durante el ataque escolar se debió a que se disparó a sí mismo, o si fue abatido por un guardia de la institución educativa.

47 En estas cifras se incluye el doble suicidio de Harris y Klebold, ocurrido en el caso Columbine (1999, EEUU, caso 16).

Diólo@os sobre Educación

año 10 | número 19 | julio-diciembre 2019 | ISSN 2007-2171 
Una de las caracterísiticas centrales de la tradición psicoanalítica del trabajo de caso ${ }^{48}$ es que opera con casos públicos, es decir, no surgidos del diván de un analista sino de cierto acto realizado por un sujeto, cuyo carácter peculiar - generalmente violento, inquietante, escandaloso, extravagante o loco- condujo a que fuera conocido por la sociedad en la que se llevó a cabo, haciendo así un pasaje al orden de lo público. ${ }^{49}$ El caso se plantea entonces como una vía privilegiada de acceso al saber del entramado social y cultural en el que el acto, desde su singularidad, se inscribió y se produjo. Es importante notar que elaborar un caso no se trata de hacer una especie de psicogénesis del acto en cuestión.

Lo anterior implica además moverse sobre al menos dos supuestos fundamentales: el primero es que todo acto - particularmente de la naturaleza recién descrita - se gesta y lleva a cabo no solo como resultado de la individualidad de un sujeto, sino también a partir de cierto conjunto de sus relaciones sociales. El segundo es que, en ese sentido, dicho acto es una forma de hacer saber algo a los otros que se encuentran en la retícula sociocultural a la que pertenece el sujeto que lo lleva a cabo.

De tal modo que el estudio de un caso entendido de esta forma, se propone ir tras las huellas del saber que ha sido dejado mediante la efectuación de un acto. Quien investiga bajo estos fundamentos -basados en la práctica clínica y la teoría analíticas a las que se articula- queda así en posición de secretario, en el sentido de la figura renacentista del que escuchaba y tomaba nota de la palabra del príncipe, localizando el saber que en ella estaba en juego y esperando el momento preciso para plantearlo de una forma que aportara conocimiento, revelándolo en su dimensión de verdad (Accetto, 2001).

No se trata pues de interpretar el acto a estudiar aplicándole un saber o una teoría previos y ajenos a su propio entramado lógico, sino de localizar el saber del que es portador al rastrear las huellas e indicios ${ }^{50}$ que ese acto —enigmático e irreductible — dejó a su paso.

Una última precisión por hacer en este apartado consiste en señalar que, si bien esta forma del estudio de caso constituye una práctica de lo singular, tiene, por otra parte, el sentido de establecer condiciones para hacer comparaciones y entablar familiaridades entre casos, en cuanto que ejemplos de una problemática a estudiar. Esto último no apunta hacia la posibilidad directa de la generalización, sino a sentar nuevas bases para la discusión teórica y clínica, y para poner a prueba las articulaciones entre la experiencia y la teoría. ${ }^{51}$

\section{Los 65 casos en esta investigación}

A partir de este necesario rodeo que da cuenta de los fundamentos metodológicos y del sentido que guía esta línea de investigación, se avanzará en precisar cuál es el modus operadi efectivo para estudiar el problema que nos ocupa, después de haber encontrado no un caso, ni unos cuantos, sino 65. En la

48 Tradición llamada también "fábrica de caso", para hacer alusión al carácter colectivo de su elaboración. Respecto de este tema se recomienda al lector: Allouch (1995b) y (1995c).

49 Dos ejemplos de ellos: Allouch (1995a) y Vindras (2002).

50 He aquí las filiaciones de este método con el llamado paradigma indicial. Cf. Ginzburg (2008: 185-239).

51 Cf. Vindras (2002: 17-32).

Diólo@os 
medida de lo posible, habrá que hacerlos contar a todos. De esa manera, se buscó en internet para recopilar todos aquellos materiales de audio, visuales y escritos que documentaban piezas de cada uno de estos casos, en forma de reportes noticiarios, artículos de opinión y de análisis, e incluso testimonios, escritos o videograbados, de los atacantes mismos. Como era de esperarse, el resultado fue distinto para la elaboración y armado de cada dosier, pues la cantidad y riqueza de los materiales relacionados con los diversos casos era muy variable y dependía generalmente del carácter, la magnitud, la gravedad y el impacto social y político que tuvo en su momento cada atentado.

¿Cómo proceder, metodológicamente hablando, ante la multitud y la heterogeneidad de casos de ataques escolares realizados por estudiantes, teniendo como referencia el estudio de caso en el psicoanálisis? La respuesta encontrada consistió en localizar, en el análisis de cada uno de los 65 casos, las coordenadas comunes que recorren su conformación y el proceso a través del cual se fueron produciendo, con el propósito de extraer sus implicaciones relativas al fenómeno a estudiar, y reflexionar sobre ellas.

Los hallazgos hechos durante la investigación, de los cuales se ha dado cuenta ya, abrieron varias preguntas que han sido planteadas a lo largo de esta exposición. En adelante, este texto se enfocará en su objetivo principal: la localización de lo que los estudiantes atacantes han hecho saber acerca de los motores y los propósitos del proyecto y la ejecución de sus ataques.

\section{El hacer saber de los motivos de los casos de ataques escolares \\ a manos de estudiantes. ¿Realmente "se quiere hacer saber algo"?}

Esta sección comienza con ciertas precisiones importantes. El estudio no se plantea tomar el diagnóstico psicopatológico de los sujetos atacantes - que en varios casos se ha dado a conocer en la red-como causa o explicación de la iniciativa de cometer un atentado escolar y de su ejecución. Aún menos se propone anteponer este diagnóstico a la exploración de lo que fue determinante en cada caso para la realización del acto en cuestión —es decir, el ataque-, puesto que hacerlo hipotecaría la posibilidad de localizar ese hacer saber en cada uno de ellos. ${ }^{52}$

De acuerdo con la información ofrecida por las fuentes consultadas, en 25 de los casos hay etiquetas diagnósticas — algunas establecidas previamente a los ataques, otras de manera ulterior-, tales como: trastorno por déficit de atención con hiperactividad (TDAH), síndrome de Asperger, autismo, dislexia, esquizofrenia, depresión, ansiedad, trastornos de personalidad, brotes psicóticos, etc. Pero en este trabajo se sostiene que estas categorías psicopatológicas, independientemente de su validez o precisión, no son capaces de dar cuenta del porqué de los actos de los perpetradores, ni pueden, por ende, aspirar a reducir a ellas eso que movió a los sujetos a llevar a cabo una acción transgresora de la envergadura de los ataques, ni el carácter que define esta acción en su sentido particular.

52 A propósito de esta cuestión, Foucault (1961: I-XI): “Ninguno de los conceptos de la psicopatología debe ejercer, ni siquiera y sobre todo en el juego implícito de las retrospecciones, un papel organizador".

Diólo@os sobre Educación

año 10 | número 19 | julio-diciembre 2019 | ISSN 2007-2171 
Intentar establecer una correlación directa entre diagnóstico y comisión del ataque introduce subrepticiamente un razonamiento circular, cerrado sobre sí mismo, que no permite repensar ni analizar la cuestión en juego. ${ }^{53}$ Por lo tanto, aún en presencia de estos ya referidos diagnósticos, se ha optado por seguir todos los indicios que el propio ensamblaje de los casos ofrece a la observación. Si el sentido es estudiar qué son los ataques de violencia escolar en función de aquello que mueve a algunos sujetos a realizarlos, más que enfocarnos en diagnósticos, conviene hacer una reconstrucción del entramado lógico-estratégico de los ataques, y tratar de esclarecer qué experiencias llevaron a los estudiantes a realizar esos actos irreductibles y difíciles de comprender, y cómo ellos mismos pensaron tales experiencias.

Así pues, lo que se plantea aquí es abrir y seguir vías alternativas de investigación mediante las cuales sea posible tratar de abordar cada uno de los casos a partir de ellos mismos, y no desde un marco conceptual externo y ajeno a ellos desde el inicio.

La segunda precisión por hacer es que el aspecto de los complejos familiares, si bien se lo supone y reconoce en este trabajo como un elemento muy importante en la composición de cada uno de los casos, no será un ámbito al que se preste atención de manera privilegiada. ${ }^{54}$ Ciertamente, desde la experiencia en la práctica analítica es posible conjeturar de forma muy general que la realización de actos graves y trascendentes, efectuados por niños, niñas, adolescentes y jóvenes, en algún sentido se encamina a interpelar a los padres o a las familias. ${ }^{55}$ Sin embargo, para el propósito e interés particulares del estudio, el hecho de que los ataques sean llevados a cabo en el marco de la escuela y la afecten de diversas e irremediables formas es un hecho irreductible, amerita ser atendido de forma específica como tal.

Aclarado lo anterior, se abordará, pues, la coordenada analítica que recorre prácticamente la totalidad del compendio casuístico, y que es el objeto del interés de este trabajo. La evidencia encontrada

53 De una manera similar procedió el presidente estadounidense Donald Trump cuando declaró, tras el ataque escolar masivo de Nikolas Cruz, ocurrido el 14 de febrero de 2018 en Florida, que se había tratado del proceder de un joven con trastornos psiquiátricos, por lo que su gobierno se encaminaría a reforzar la atención a los problemas de salud mental en su país. Es decir, de acuerdo con este planteamiento, el joven actuó como lo hizo porque "tenía problemas psiquiátricos". Con la emisión de ese juicio que aludía solamente a un diagnóstico psicopatológico, se acabó toda problematización posible; de hecho, fue de ese modo como Trump se negó a considerar este ataque en relación con las ugentes iniciativas para el Congreso de adoptar políticas de mayor control sobre las armas de fuego.

54 No obstante, en siete casos este es un ámbito particularmente importante, pues el atentado escolar fue antecedido por graves ataques contra familiares, como un incendio en la casa familiar, el asesinato de uno o ambos padres, o de una figura sustituta —abuelo o madrastra- , y el asesinato de hermanos (estos casos corresponden a los casos 1, 12, 15, 25, 43, 44 y 45 en el cuadro 1).

55 En muchas ocasiones, estos actos en efecto interpelan a los padres y familiares, aunque esto generalmente no se hace manifiesto ni llega a ser parte del dominio público. Un ejemplo muy claro de esto es caso 16 , correspondiente al ataque a la preparatoria de Columbine, Colorado (1999, EEUU). Sue Klebold, la madre de Dylan Klebold, uno de los jóvenes atacantes, decidió romper el silencio tras el ataque y hacer declaraciones públicas sobre las acciones de su hijo, y reconocer que ella había sido incauta y había omitido las señales alarmantes que Dylan había mostrado por años. De hecho, poco después del ataque, Sue Klenbold escribió un libro sobre estos temas, cuyas regalías son donadas a causas sociales.

Diólo@os 
a través del análisis de la información de $60^{56}$ de los casos estudiados sugiere la existencia de razones envueltas o entreveradas ${ }^{57}$ en la comisión de los ataques, las cuales les dan a estos un cierto carácter o sentido. Generalmente, dichas razones son encontradas mediante las siguientes vías: la reconstrucción histórica de los hechos, las declaraciones y los testimonios de los perpetradores, efectuadas antes, durante o después de los ataques, en diferentes contextos y por distintos medios. ${ }^{58}$

Como ya se ha dicho, es imposible llevar a cabo en este espacio un estudio caso por caso. Pero la información ofrecida por las versiones estudiadas de los 60 casos que han dejado entrever aquello que llevó a los atacantes a actuar como lo hicieron plantea, de forma general, cinco dimensiones distintas y relacionadas entre sí. El despliegue de estas dimensiones que se efectuará enseguida apunta a poner de manifiesto cómo todas ellas se encuentran presentes en diversas proporciones en la ensambladura de cada uno de los casos, a manera de matices distintos que el perpetrador otorga - generalmente sin saberlo—al sentido de su acto-atentado. ${ }^{59}$

No obstante, debido al orden de realidad subjetiva en el que estas dimensiones se inscriben, dicha proporción no es mesurable; pero la información recabada acerca de la preparación y la ejecución de los ataques generalmente arroja indicios al respecto, de tal modo que cierta dimensión parece predominar sobre las otras. Veamos.

\section{Primera dimensión: responder a la pérdida de componentes fundamentales de sí mismo}

Una dimensión de los ataques consiste en que son planeados y ejecutados como una acción de respuesta ante pérdidas morales y materiales — o patentes amenazas de ellas — sufridas por los sujetos atacantes; pérdidas relacionadas con aquellos elementos y bienes en que se basa la propia valía, y que son imprescindibles para el sostenimiento de sí. En los 60 casos estudiados en los que se localizaron motivos rastreables en la producción del ataque armado, fue localizada en medidas variables esta dimensión que se nombrará aquí como la dimensión de las pérdidas insoportables, las cuales, por supuesto, incluyen la pérdida de la perspectiva o esperanza de tener una vida vivible. Dichas pérdidas se relacionan con el efecto del hecho de que los perpetradores fueron objeto de múltiples formas de exclusión continuamente: marginación, intimidación, deshonra, humillación, rechazo, abandono, maltrato físico y subjetivo, abuso,

56 En cuatro de los casos restantes, precisamente algunos de los más recientes (casos 52, 59, 62 y 63) no se obtuvieron datos suficientes para esclarecer la posibilidad de motivos; y el caso 42 deja la extraña impresión de haberse tratado de un atentado en apariencia "inmotivado". Véase cuadro 1 en este artículo, para cotejar de qué casos se trata.

57 Se nombra de estas maneras la relación de dichas "razones" con los actos de violencia armada perpetrados con el fin de relativizar y problematizar toda posibilidad de hablar de relaciones explicativas "causa-efecto", que tanto tienta sobre todo al aparato jurídico y a las disciplinas "psi", al momento de abordar este tipo de problemas.

58 Se hace referencia, por ejemplo, a notas escritas por los perpetradores, videograbaciones subidas por ellos a internet, comentarios suyos hechos a terceros, sus testimonios judiciales, etcétera.

59 Debido a lo anterior, resultará difícil sopesar cuantitativamente la proporción precisa del valor de cada una de estas dimensiones, así como también establecer la frontera divisoria entre unas y otras.

Dióloqos 
acoso, traición, etc. Estas formas de exclusión resultaron finalmente intolerables para los perpetradores, quienes se encontraban bajo condiciones como las siguientes:

- Teniendo experiencias de fracaso escolar, y de fracaso también en el nivel de las relaciones eróticas y amorosas, e incluso laboral en el caso de algunos adolescentes y jóvenes preuniversitarios o universitarios.

- Pensando que ellos mismos padecen desventajas insuperables relacionadas con su conformación corporal, subjetiva, social o cultural, como tener una característica física considerada como un defecto, haber sido diagnosticados con Asperger, ser de una raza o etnia distintas a la mayoría de las personas a su alrededor, provenir de estratos sociales inferiores a los de los demás, etcétera.

- Padeciendo el rompimiento de relaciones importantes con seres queridos, a causa de conflictos en apariencia insalvables como rupturas o mudanzas, e incluso la pérdida de seres queridos a causa de su muerte.

Uno de los casos paradigmáticos de esta primera dimensión es el del ataque de Charles Andrew WiIliams (15 años, caso 19) a la Escuela Superior de Santana, California, EEUU, el 5 de marzo de 2001. Disparó con un arma de fuego en varias zonas de la escuela, asesinando a dos estudiantes e hiriendo a 13 más. En su declaración judicial dijo que estaba cansado de ser objeto de bullying por parte de sus compañeros de escuela. Previamente había intentado hablar del problema con un consejero escolar, quien no pudo recibirlo "porque estaba ocupado". También les había comunicado a sus amigos que esa situación le impedía desear seguir viviendo. Poco antes del atentado que realizó, un maestro lo había humillado ${ }^{60}$ frente a su grupo de clases. Sus padres se habían separado recientemente, por lo que había ido a vivir con su padre en Santana, y era nuevo en su escuela. Antes del tiroteo, el joven le escribió a él una nota diciéndole: "Lo intenté muy duro, y llegué tan lejos, pero al final realmente no importa”. Al término de su ataque, fue encontrado intentando dispararse a sí mismo, sin haberlo logrado.

Esta primera e importante dimensión analítica en el estudio del fenómeno de los ataques armados en instituciones educativas - dirigida a pensar el ataque como una respuesta a pérdidas insoportablesencuentra resonancia y convergencia en algunos hallazgos efectuados por otros estudiosos y críticos del tema. Uno de ellos es Langman (2015), doctor en psicología, quien en su obra School Shooters discute el papel motor de ciertos hechos vividos por los perpetradores, los cuales amenazan parte de su constitución subjetiva más fundamental, como hechos relacionados con sus características corporales y personales, y ataques o cuestionamientos a sus identidades de género, particularmente la masculina.

60 Se desconocen las circunstancias en que se dio la presunta humillación.

Diálopos

sobre Educación

temas actuant año 10 | número 19|julio-diciembre 2019 | ISSN 2007-2171

18 
Desde una perspectiva de la antropología social, el profesor Leyton, experto en el estudio de asesinatos en serie, señala ${ }^{61}$ que varios de los tiroteos escolares han sido realizados por inmigrantes o hijos de ellos, apuntando de este modo al posible papel que jugaron en la producción de algunos ataques la exclusión y la marginación de la que los inmigrantes han sido objeto por generaciones enteras debido a ideologías racistas. Consecuentemente, Leyton resalta la importancia de tomar el fenómeno de los ataques desde una perspectiva no individualista ni psicologizante, que impulse a los países a efectuar un examen de las actitudes gubernamentales y sociales que pudieran estar en la base del problema.

Desde una plataforma crítica distinta, Keith Rock — joven nativo estadounidense-, a partir de un interesante análisis del contexto sociocultural del atentado escolar perpetrado por Jeffrey Weise en Red Lake, EEUU, en 2005 (caso 25), en un documental sobre Weise dirigido por él, 62 propone el concepto de legión para pensar, agrupar e incluso hermanar la experiencia de los individuos que, por razones raciales y de otra índole, viven en la más completa marginación social y abandono dentro de su propia nación. Los jóvenes atacantes escolares, dice Rock en su documental, pertenecen precisamente a la legión, definida como: "Subsuelo mental de personas de la oscuridad. Gente que sabe quién es, y la legión es tu familia desconocida que nadie puede ver salvo tú. Es el colectivo de solitarios".

Considerando que este concepto abre una senda fecunda e importante de problematización sobre el tema de este trabajo, podría añadirse a la definición que Rock hace de él, que la legión congrega - tal vez podría decirse que justo desde la pérdida - a los llamados loosers, outsiders, outcasts, weirdos, y lonners ${ }^{63}$ (perdedores, marginados, parias, raros y solitarios). Legión se refiere generalmente a una gran cantidad de personas localizadas en un lugar determinado; pero hay que tomar en cuenta el siguiente hecho: históricamente, este término ha designado a grupos militares especializados y de élite que habían sido cooptados por estados colonizadores, y que en realidad conformaban ejércitos de individuos que originalmente pertenecían a pueblos extranjeros subordinados o a grupos marginales.

Entonces habría que preguntar: ¿Legión designa a un grupo cuyos miembros se oponen a su segregación y a sus segregadores, y luchan contra ellos? E intentando seguir los argumentos de base en la perspectiva de Rock, ¿los ataques responderían a la rebeldía manifestada contra cierta configuración de relaciones de poder en la cual los perpetradores se hallaban cautivos? ${ }^{64}$

61 Cf. la siguiente entrevista del profesor Leyton para CBC News: https://www.cbc.ca/news2/yourinterview/2007/04/anthropologist-andauthor-elliott-leyton-on-the-virginia-tech-shootings.html

62 Cf. https://youtu.be/_TcULXeFA6E

63 Curiosamente, son adjetivos en lengua inglesa que suelen utilizarse -incluso en países de lengua distinta - para identificar a estos individuos o grupos a los que se les impone la exclusión. ¿Acaso se ha vuelto la lengua —aunque sea solo pretendidamente- del que segrega? 64 Este sentido bélico o de guerra en el término de Legión, que va acompañado de una condición simultánea de segregación, no es ajeno a uno de los significados, por ejemplo, que la Biblia cristiana le otorga: "ejército de demonios". Por otra parte, curiosamente, Federico Guevara, el primer adolescente mexicano que llevó a cabo un atentado escolar masivo en Monterrey, N. L, en 2017 (caso 57), formaba parte de una página de Facebook denominada Hail Legión Holk, presuntamente dirigida a preadolescentes y adolescentes interesados en promover el desorden y caos social.

Diólopos 
Por lo pronto, recapitulando los elementos hasta aquí presentados a propósito de esta primera dimensión, es posible establecer que las pérdidas de sí —o amenazas de estasde la envergadura ya descrita - como lo es el hecho de ser objeto de opresión, exclusión y segregación-, bajo ciertas circunstancias pueden plantear, efectivamente, para individuos como los jóvenes atacantes escolares, la posibilidad de responder a quienes les han desposeído de esas maneras. Si bien puede considerarse que el carácter de esas desposesiones o pérdidas es simbólico en principio, es importante reconocer que tienen efectos reales en las vidas (Butler, 2005) de esos estudiantes perpetradores, y que pueden mover a despliegues bélicos que, evidentemente, incluyen el uso efectivo de armas. Dichas formas de respuesta, como lo habrá insinuado Rock, se vinculan de diversas maneras con atentados semejantes efectuados anteriormente por otros jóvenes, como expansiones múltiples y sucesivas, en el espacio y el tiempo, de una guerrilla. Este último punto conduce al planteamiento de la segunda dimensión.

\section{Segunda dimensión: efectuar una rebelión}

Esta segunda dimensión de los ataques consiste en el hecho de que los atacantes fueron movidos por el imperioso impulso de sublevarse, a manera de acto de ajuste de fuerzas restitutivo del propio lugar subjetivo, en el conglomerado de las relaciones de poder en las cuales estuvieron insertos a partir de la dimensión de la pérdida. Tiene que ver con hacerse contar y darse a respetar, con desplegar una superioridad apabullante ante los rivales y enemigos que les han hecho daño.

En relación con esto, vale la pena señalar que en los diferentes casos estudiados de ataques escolares esta restitución se caracteriza claramente por el uso de los recursos armamentistas, tecnológicos, estratégicos y retóricos de su época. Particularmente, la aparición de internet y de las redes sociales en la década de los noventa como instrumentos de acceso al conocimiento y la información, así como de expresión y comunicación con otros, ha dado posibilidades performativas inéditas a los planes de atentados escolares perpetrados por menores de edad y por jóvenes. ${ }^{65}$

Uno de los entonces casos paradigmáticos de esta segunda dimensión es el llamado "Masacre en Columbine", perpetrado en Colorado, EEUU, en 1999. Dos estudiantes de la escuela preparatoria Columbine, Eric Harris y Dylan Klebold, de 18 y 17 años respectivamente, amigos entre sí, tras haber planeado largamente un atentado en su escuela, el cual, presuntamente pretendía tener alcances de destrucción masiva similares a los del atentado en Oklahoma City en 1995, Ilegaron fuertemente armados a la preparatoria e instalaron varias bombas de fabricación casera. Sin embargo, algunos de los artefactos no explotaron y, al ver frustrados sus planes originales, los jóvenes acometieron entonces el edificio con sus armas y mataron a 12 estudiantes y a un profesor, e hirieron a más de una veintena de alumnos y

65 Esto en el sentido que señala Butler (2005), donde la performatividad se entiende no tanto como aquello que se hace a partir de las palabras, sino del valor prescritivo o normativo que plantea la iterabilidad de los discursos y de los hechos que se derivan de ellos; es decir, por el solo efecto de su repetición, ocultando la historicidad de la cual son producto. En efecto, esto mismo fue apuntado de otra manera por Sue Klebold, la madre de Dylan Klebold (Columbine, 1999): "Unos (atacantes) aprenden de otros...."

Diólo@os 
algunos maestros. Enterados de que la policía ya se encontraba en camino, juntos y arrodillados frente a una de las cámaras de la escuela, los dos jóvenes se suicidaron dándose a sí mismos un tiro en la cabeza. La información recabada indica que ambos habían sido objeto constante de intimidaciones, insultos y rechazo por algunos grupos de estudiantes llamados jocks (atletas y entusiastas de los deportes), quienes decían que Klebold y Harris "eran raros, no eran chicos normales", se vestían diferente, eran torpes en las actividades deportivas y no eran populares entre los preparatorianos de Columbine. De hecho, los apodaban outcasts, o sea, "parias".

En la red se encuentran todavía circulando videos que los dos jóvenes subieron para ensayar y difundir sus planes del atentado, como performances en los que actuaban como "chicos malos y vengadores" que amenazaban y amedrentaban a sus enemigos, al estilo cinematográfico hollywoodense de su época.

\section{Tercera dimensión: buscar efectuar una venganza}

Esta dimensión se relaciona sobre todo con los atentados en los que el énfasis del acto mismo parece estar puesto en la realización de una venganza o ajuste de cuentas, a manera de devolución violenta de un daño recibido — realmente o como amenaza — hacia quien lo impuso.

Un caso ejemplar de este giro en el sentido del ataque parece ser el de la llamada "Masacre de Erfurt", perpetrada en Alemania el 26 de abril de 2002 por el estudiante Robert Steinhäuser, de 19 años (caso 20). El joven había sido expulsado de su escuela, Gutenberg-gymnasium, sin derecho a obtener calificaciones, por haberse ausentado de la escuela para ir a un club de tiro, y había entregado justificantes médicos apócrifos durante los días en los que debía presentar los exámenes reprobados el año anterior. De acuerdo con la exigente normatividad del Estado de Turingia, para el joven Steinhäuser se habían terminado las posibilidades de cursar nuevamente las materias requeridas para finalizar la preparatoria y, por lo tanto, de acceder posteriormente a estudios universitarios y de aspirar a obtener un buen empleo. Así, humillado y sin salida, vestido con una especie de disfraz negro de ninja, se dirigió armado al que había sido su plantel educativo y comenzó a disparar, recorriendo cada salón y matando a 13 profesores, un policía y dos estudiantes, e hiriendo a siete personas. Al final del atentado se suicidó.

\section{Cuarta dimensión: hacerse reconocer por los otros}

\section{y por la autoridad mediante la fuerza, lanzándoles un problema capital}

Aquí se congregan los casos en que el modus operandi del atentado muestra una intención principalmente retórica, aunque las otras dimensiones puedan también estar presentes. Es decir, para el joven perpetrador principalmente se trata de lanzar a la institución escolar un grave problema existencial —el cual estará relacionado a las pérdidas descritas en la primera dimensión - a través de las balas o del despliegue de armas, para hacer que las autoridades y la colectividad involucradas lo reconozcan mediante el proyecto y realización del ataque.

Diólo@os sobre Educación año 10 | número 19 | julio-diciembre 2019 | ISSN 2007-2171 
Esta vez, un ejemplo significativo de esta dimensión es el caso de la llamada "Masacre en Virginia Tech", en Virginia, EEUU, perpetrada el 16 de abril de 2007 por el estudiante surcoreano Seung-Hui Cho, de 23 años (caso 29). Todo indica que el joven tenía serios problemas en el dominio considerado correcto del idioma inglés, lo que le ocasionaba ser objeto de burlas, rechazo y marginación por parte de los estudiantes, y en particular de las jóvenes universitarias, quienes lo desdeñaban cuando él intentaba acercarse a ellas. Instantes antes de llevar a cabo el ataque, compiló una especie de manifiesto multimedia ${ }^{66}$ que envió a la cadena de noticias de la NBC News, en el cual incluía un texto en el que explicaba el sentido de su acto, fotografías suyas portando armas en distintas posiciones - apuntando al observador o hacia sí mismo-, y videos en los que explicaba el porqué de lo que haría. Varios fragmentos de este manifiesto se encuentran en la red. He aquí una parte de lo que Cho explicó en sus videos:

Cuando llegó la hora, lo hice. Tuve que hacerlo. Había miles de oportunidades y de formas de evitar esto hoy. Pero ustedes decidieron derramar mi sangre. Me acorralaron en una esquina y me dieron solo una opción. La decisión era de ustedes. Ahora hay sangre en sus manos que nunca lavarán.

Cho asesinó a 27 estudiantes y cinco profesores, e hirió a 29 personas más con un arma de fuego. Finalizó con su suicidio. Testigos de la masacre revelan que el joven corría por los pasillos preguntando "¿Dónde está mi novia?", y enseguida disparaba.

Un ejemplo más de esta dimensión es el caso de Luke Woodham, atacante escolar en Misisipi, EEUU, 1997 (caso 12), del que solo citaré una nota que el atacante escribió justo antes de emprender su atentado contra Escuela Secundaria Pearl River Central, en donde estudiaba.

No estoy loco, estoy enojado. Maté porque la gente como yo es maltratada cada día. Hice esto para mostrar a la sociedad que nos presiona y presionaremos de regreso. Toda mi vida fui ridiculizado, siempre golpeado, siempre odiado. ¿Puedes tú, sociedad, culparme realmente por lo que hago? Sí, sí lo harás... No fue un ruego de atención, no fue un ruego de ayuda. Fue un grito de pura agonía diciendo que no puedes abrir los ojos, si no puedo hacerlo mediante el pacifismo, si no puedo hacerles ver mediante el despliegue de inteligencia, entonces lo haré con una bala. ${ }^{67}$

\section{Quinta dimensión: intentar dar una solución final68 al problema vital que padece}

En esta última dimensión, el acto-atentado apareció para el perpetrador como la única solución o salida que le quedaba frente a una situación problemática que era imposible seguir soportando.

Caso ejemplar de esta dimensión es el atentado llevado a cabo por Brandon David Mclnerney, de 14 años, en su escuela secundaria en Oxnard, California, EEUU, el 12 de febrero de 2008 (caso 32). Dentro

66 Tal fue el concepto con el que fue denominado por un locutor de la NBC. Cf. https://www.youtube.com/watch?v=8AQq03PSD-w y Hauser (18 de abril de 2007).

67 Anónimo (8 de octubre, 1997).

68 Alusión a una especie de reviraje de la solución nazi tomada contra la llamada "cuestión judía".

Diólo os 
de su escuela, el adolescente empuñó un arma de fuego y disparó en la cabeza a un compañero suyo, de 15 años de edad, causándole muerte cerebral, y dos días después, la muerte definitiva. Inicialmente se pensó que el móvil había sido la homofobia, pues el joven muerto era abiertamente homosexual e iba travestido a la escuela; pero posteriormente se reconoció que la víctima buscaba provocar a Mclnerney; lo acosaba e intentaba seducirlo incluso delante de sus compañeros, por lo que había comenzado a ser objeto de burlas en la escuela.

\section{Discusión y reflexiones finales. Pensar esas balas que no han llegado a su destino. Del problema de vidas nuevas que se tornaron invivibles...}

Frente al problema que este artículo se ha planteado abordar, ¿cuál es el valor heurístico del hallazgo de cada una de estas cinco dimensiones localizadas en lo que los estudiantes de los casos estudiados hacen saber acerca de sus motivos? ¿Tiene alguna de ellas un potencial que permita organizar a las otras, y hacerlas gravitar alrededor suyo?

Guilles Deleuze y Félix Guattari (2002: 359-432) han introducido una importante perspectiva filosófico-política para pensar la cuestión de las diversas formas de violencia extrema, a partir de su concepto llamado máquina de guerra, el cual designa la acción que un individuo o un grupo emprende para defender, recuperar o ganar un territorio existencial ${ }^{69}$ amenazado o invadido. La máquina de guerra es una forma de sublevación cuya legalidad proviene de la afirmación de la vida en su radical singularidad, así como de una lucha inherente por mantener ambas — vida y singularidad-, aunque, paradójica y necesariamente, sublevarse implique ponerlas en riesgo.

Este concepto se refiere, por lo tanto, a una manera de buscar cómo continuar habitando un lugar en la Tierra, a pesar de los obstáculos interpuestos por los otros contrincantes que en esa trayectoria juegan un papel dominante y oprimen. En consecuencia, la máquina de guerra pugna por impedir la anulación, y por hacer viable el hecho de aparecer frente a los otros que son opresores. Evidentemente, esto conlleva la invención, implementación y el uso de instrumentos, armas y estrategias de ataque.

De acuerdo con Deleuze y Guattari, el origen de esta forma de acción radical en la historia de la humanidad se localiza específicamente en las tribus y sociedades nómadas. Y es precisamente frente y en relación con ese devenir originario de la máquina de guerra que se erigió el antiquísimo orden social del Estado, cuyos cuerpos militares se han apropiado de ese dispositivo de fuerza original del oprimido. Sin embargo, la máquina de guerra ha sido un modo de acción y rebeldía que es vigente aun en la actualidad, entre los individuos, grupos o pueblos que han sido excluidos y sujetos al poder de sociedades, instituciones y culturas dominantes. De hecho, un elemento clave para este estudio es el punto donde Deleuze y Guattari señalan que la puesta en marcha de esta máquina responde y se orienta por la aparición y el abordaje de problemas. En efecto, sabemos que, a través del tiempo,

69 Territorio que siempre es móvil, de acuerdo con los autores.

Diólopos sobre Educación año 10 | número 19 | julio-diciembre 2019 | ISSN 2007-2171 
para ciertos pueblos y grupos de excluidos, sujetos al dominio e incluso a la aniquilación por parte de otros pueblos, estados o imperios, el problema de la exclusión y de la opresión es y ha sido uno de los principales motores de guerras y revoluciones. Como lo señalan los autores, la etimología griega del término problema guarda consigo la huella silenciosa de esa "historia": pro significa "adelante", y ballein "arrojar con fuerza".

¿Nos acercamos de esta manera a la clase de problemas que habitan a quienes conforman la llamada legión, propuesta por Keith Rock a propósito de ese "oscuro subsuelo mental del colectivo de solitarios", en el que se agrupan menores y jóvenes como algunos school shooters? ¿Los ataques de estos últimos son entonces el lanzamiento de una clase de problemas que no han podido formularse ni abordarse políticamente —en un sentido arendtiano—, ${ }^{70}$ sino únicamente por vía de la puesta en marcha de la máquina de guerra? Pero ¿qué pensar al respecto, cuando esto comienza a ocurrir apenas seis décadas atrás, precisamente en el seno de la institución escolar donde se supone que se prepara y se forma a las nuevas generaciones a contribuir en la construcción de un mundo común, para todos?

Al costado de esta serie de preguntas abiertas a propósito de la teorización acerca de la máquina de guerra, queda entonces la cuarta de las dimensiones localizadas en el hacer saber de los porqués de los estudiantes - aquella relacionada al hacerse reconocer por los otros y la autoridad, mediante la fuerza, lanzándole un problema capital - como la dimensión que organiza y representa de mejor manera el complejo movimiento de estos actos de violencia extrema. En efecto, de acuerdo con los 60 casos catalogados como motivados, es indudable que, para cada uno de los perpetradores, de lo que se trataba el ataque escolar era de llevar a cabo una cuestión nodal: el lanzamiento de un problema de enorme envergadura - como no saber cómo vivir en este mundo y tener una vida vivible- con la fuerza de las armas.

¿Esto va de la mano con el hallazgo de los elevados porcentajes de suicidio — directo o indirecto, como ya se ha dicho- en la mecánica de estos ataques?

¿Acaso están a la altura de esta compleja problemática de nuestro tiempo, que es también el de los niños, adolescentes y jóvenes atacantes escolares, las razones de Estado con las que se suelen enfrentar los ataques, y sus medidas punitivas y preventivas - como las renovadas regulaciones para el control de armas y las "operaciones mochila", implementadas mientras los mercados de armas sonríen-, en nombre precisamente de unas leyes y un sistema que los perpetradores interpelan con su acto?

Foucault, en un artículo escrito en 1979, titulado "¿Es inútil sublevarse?", señala una dirección mínima e importante al respecto:

Las sublevaciones pertenecen a la historia. Pero, en cierto modo, se le escapan. El movimiento mediante el cual un solo hombre, un grupo, una minoría o un pueblo entero dice: «no obedezco más», y arroja a la

70 Sentido expuesto en el tercer epígrafe a este trabajo: "La política es la posibilidad de un ámbito plural, en el que quienes participan, se revelan como alguien y le otorgan durabilidad al mundo." Cf. Arendt (1998).

Diáloqos 
cara de un poder que estima injusto el riesgo de su vida [sic.] — tal movimiento me parece irreductible. Y ello porque ningún poder es capaz de tornarlo absolutamente imposible: [...] Y también porque el hombre que se alza carece finalmente de explicación; hace falta un desgarramiento que interrumpa el hilo de la historia, y sus largas cadenas de razones, para que un hombre pueda «realmente» preferir el riesgo de la muerte a la certeza de tener que obedecer (Foucault, 2013: 861).

Es decir, lo menos que hay por hacer al respecto es saber tomar nota de los enigmas de esa violencia, como condición indispensable para comenzar a abordar los problemas que de ese modo nos están siendo lanzados...

\section{Referencias}

Accetto, T. (2001). De la disimulación honesta. México: Escuela Lacaniana de Psicoanálisis.

Agamben, G. (2004). Infancia e historia. Buenos Aires: Adriana Hidalgo.

Ajam, K. (23 de agosto, 2008). Sword Attack was 'Carefully Planned'. IOL News. https://www.iol.co.za/ news/south-africa/sword-attack-was-carefully-planned-413575

Allouch, J. et al. (1995a). El doble crimen de las hermanas Papin. México: Libros de Artefacto. (1995b). Freud y después Lacan. Buenos Aires: Edelp. (1995c). Margueritte. Lacan la llamaba Aimée. México: SITESA-EPEELE.

Anónimo (8 de octubre, 1997). Six Mississippi Teens Charged in High School Shooting Spree. The Washington Post. https://www.washingtonpost.com/archive/politics/1997/10/08/six-mississippi-teenscharged-in-high-school-shooting-spree/090fb960-a9e4-4f75-b7a0-235337ebd32d/?utm term =. fe3a3a7b4a90

(2 de junio, 2004). Japan in Shock at School Murder. BBC News. http://news.bbc.co.uk/2/hi/asiapacific/3768983.stm

(11 de abril de 2009). Student Shoots Three in Spree and Then Kills Self. Ekathimerini. http://www. ekathimerini.com/62847/article/ekathimerini/news/student-shoots-three-in-spree-then-kills-self (23 de septiembre, 2011). Un niño de 10 años de una escuela pública de Sao Paulo disparó varias veces contra su maestra y luego se suicidó. Cuatro. https://www.cuatro.com/noticias/nino-10 anosdispara a su profesora y se suicida-brasil 0 1289400043.html (10 de diciembre, 2011). Mystery Over What Drove Virigina Tech Gunman to Snap as Friends Say He Was a Quiet Student Who Never Hinted at Violence. Daily Mail. https://www.dailymail.co.uk/news/ article-2072694/Ross-Truett-Ashley-Mystery-Virginia-Tech-gunman-snap.html (20 de junio, 2014). El adolescente Édgar Yoevani, de 15 años de edad, fue condenado a ocho años de prisión por asesinar a Ricardo Alvarado Ordóñez, de 13. Proceso. https://www.proceso.com. $\mathrm{mx} / 375203 /$ dictan-8-anos-de-prision-a-adolescente-que-asesino-a-companero-de-secundaria

Diólo@os sobre Educación

año 10 | número 19 | julio-diciembre 2019 | ISSN 2007-2171 
(30 de diciembre, 2014). Joven muere en Rusia por bullying tras convulsionarse. Excelsior. https:// www.excelsior.com.mx/global/2014/12/30/1000216

(25 de septiembre, 2015). 1 Dead 1 Critical in School Gunfire. Saint Paul Pioneer Press. http:// nl.newsbank.com/nl-search/we/Archives?p product=PD\&s site=twincities\&p multi=SP\&p theme $=$ realcities $\& p$ action $=$ search $\& p$ maxdocs $=200 \& p$ topdoc $=1 \& p$ text direct$0=0 F D D E 6 C 060 F A D A C A \& p$ field_direct-0 $=$ document_id\&p_perpage $=10 \& p$ sort $=Y M D$ date:D\&s trackval=GooglePM

(22 de noviembre, 2016). Das Tagebuch von Sebastian B. Stern. https://www.stern.de/panorama/ weltgeschehen/amoklauf-von-emsdetten-das-tagebuch-von-sebastian-b--3327962.html (8 de agosto, 2017). La muerte de una joven de 15 años que se suicidó en su colegio estremece a Argentina. CNN Español. https://cnnespanol.cnn.com/2017/08/08/lara-la-plata-suicidio-argentinaalumna-disparo-muerte-colegio-rafael-hernandez/

(20 de marzo, 2018). Austin Wyatt Rollins Identified as Great Mills Highschool Schooter. The Washington Times. https://www.washingtontimes.com/news/2018/mar/20/austin-wyatt-rollinsidentified-great-mills-high-s/

(19 de enero, 2018). Ax Wielding Teen Injuries Seven at Siberian School. Radio Free Europe/Radio Liberty. https://www.rferl.org/a/russia-ax-attack-school-buryatia/28984464.html

(15 de febrero de 2018). Junior y la matanza en una escuela de Patagones. El día. https://www.eldia. com/nota/2018-2-15-1-32-45-junior-y-la-matanza-en-una-escuela-de-patagones-el-mundo

Arendt, H. (1998). ¿Qué es la política? Barcelona: Paidós (2016). Entre el pasado y el futuro. Ocho ejercicios sobre la reflexión política. Barcelona: Península.

Blanchar, C. y A. L. Congostrina (20 de abril, 2015). Ataque con ballesta en Barcelona. La víctima mortal, un sustituto que Ilevaba dos semanas. El País. https://elpais.com/ccaa/2015/04/20/catalunya/1429520415_197341.html

Bryant, M. (23 de octubre, 2015). Race-Hate Links of Sweden 'Darth Vader' Murderer Probed by Police. Evening Standard. https://www.standard.co.uk/news/world/racehate-links-of-sweden-darth-vadermurderer-probed-by-police-a3097401.html

Butler, J. (2005). Cuerpos que importan. Sobre los límites materiales y discursivos del "sexo". Argentina: Paidós.

Campos Garza, L. (18 de enero, 2017). Declaran muerte cerebral de alumno agresor; los padres donarán sus órganos. Proceso. https://www.proceso.com.mx/470609/declaran-muerte-cerebral-alumnoagresor-sus-padres-donaran-sus-organos

Corbett, K. (6 de diciembre, 2017). The Murder Over a Girl. Huffington Post. https://www.huffingtonpost. com/thought-matters/a-murder-over-a-girl b 9595260. html

Deleuze, G. y F. Guattari (2002). Mil mesetas. Capitalismo y esquizofrenia. España: Pre-textos.

Dodge, J. (29 de octubre, 2014). Cody Cousins, Who Fatally Shot Purdue Student, Found Dead in Prision. CBS Chicago. https://chicago.cbslocal.com/2014/10/29/cody-cousins-who-fatally-shot-purdue-student-found-dead-in-prison/

Diólo@os 
Donaghue, E. (5 de septiembre, 2015). Texas High School Stabbing Update. CBS News. https://www. cbsnews.com/news/texas-high-school-stabbing-update-fatal-altercation-started-when-victimand-alleged-killer-bumped-shoulders-in-school-cafeteria-report-says/

Dos Santos Coelho, G. (4 de agosto, 2015). Pantriste y el despertar sangriento al problema del bullying. Clarín. https://www.clarin.com/ultimo-momento/argentina-desperto-sangre-problema-bullying 0 r1aWHFPXI.html

Finley, L. L. (2014) School Violence: A Reference Handbook. California: ABC-CLIO.

Foucault, M. (1961). Historia de la locura en la época clásica. París: Plon.

(2013). Obras esenciales. Barcelona: Paidós.

Ginzburg, C. (2008). Mitos, emblemas, indicios. Morfología e historia. Barcelona: Gedisa.

Gostanian, A., A. Johnson y C. Siemaszko (23 de enero, 2018). Kentucky School Shooting: Two Dead After Atack at Marshall County High School. NBC News. https://www.nbcnews.com/news/us-news/onedead-after-shooting-kentucky-high-school-multiple-victims-reported-n840171

Guattari, F. y S. Rolnik (2006). Micropolítica: Cartografías del deseo. Madrid: Queimada Gráficas.

Hauser, C. (18 de abril, 2007). Gunman Sent Photos, Video and Writings to NBC. The New York Times. https://www.nytimes.com/2007/04/18/us/18cnd-virginia.html

Hughes, M. (2 de diciembre, 2013). British-born Teacher Hailed as Hero of Wyoming Bow and Arrow Attack. The Telegraph. https://www.telegraph.co.uk/news/worldnews/northamerica/usa/9717501/ British-born-teacher-hailed-as-hero-of-Wyoming-bow-and-arrow-attack.html

Langman, P. (2015). School Shooters. London: Rowman \& Littlefiled.

McFadden, R. D. (31 de diciembre, 1974). 3 Killed and 9 Wounded By an Upstate Sniper, 18. The New York Times, 1. https://www.nytimes.com/1974/12/31/archives/3-killed-and-9-wounded-by-an-upstatesniper-18-3-killed-and-9.html

Paxtor, E. (21 de abril, 2015). Pánico en colegio por disparos hechos por estudiante. Prensa Libre. https:// www.prensalibre.com/ciudades/chiquimula/panico-en-colegio-por-disparos-hechos-por-estudiante/

Pidd, H. (3 de noviembre, 2014). Will Cornick Named and Jailed: The Boy Who Killed His Teacher. The Guardian. https://www.theguardian.com/uk-news/2014/nov/03/will-cornick-leeds-ann-maguire-murdered-teacher-jail

School Shooters.info (Base de datos electrónica). https://schoolshooters.info

Solomon, D. (3 de mayo, 2017). There Have Been Two More Violent Attacks at Texas Schools Since Monday's Stabbing at UT. Texas Monthly. https://www.texasmonthly.com/the-daily-post/two-violent-attacks-texas-schools-since-mondays-stabbing-ut/

Stewart, W. (3 de febrero, 2014). Student Gunman Kills Policeman and Teacher in Hostage Takeover of Class of 20 Students in School Near Moscow. Daily Mail. https://www.dailymail.co.uk/news/article-2550822/BREAKING-NEWS-Gunman-kills-policeman-takes-class-24-teenage-students-hostageMoscow-school.html

Diólo@os 
Vindras, A. M. (2002). Ernst Wagner. ¡Ecce animal!: pastor, maestro, masacrador, dramaturgo. México: Artefacto.

Zhi, Z. y H. Yiming (17 de marzo, 2004). Student Killer an Introvert Who Finally Cracks. China Daily. http:// www.chinadaily.com.cn/english/doc/2004-03/17/content_315545.htm 